\title{
Fecaloma in an iatrogenic diverticulum: an unusual complication of the procedure for prolapsed hemorrhoids (PPH)
}

\author{
A. Serventi • P. C. Rassu • E. Giaminardi • \\ G. C. Vitali - G. Brigli
}

Received: 26 May 2010/ Accepted: 19 July 2010/Published online: 20 August 2010

(C) Springer-Verlag 2010

The procedure for prolapsed hemorrhoids (PPH) is associated with low levels of postoperative pain but may be followed by unusual and severe postoperative complications.

We report a case of a 62-year-old woman affected by tenesmus, obstructed defecation and vaginal bulging 2 years after a PPH procedure performed in another institution. Clinical examination and colonoscopy revealed a mass within the anterior rectal wall bulging into the vaginal and rectum lumen $3 \mathrm{~cm}$ above the dental line, mimicking a stromal tumor.

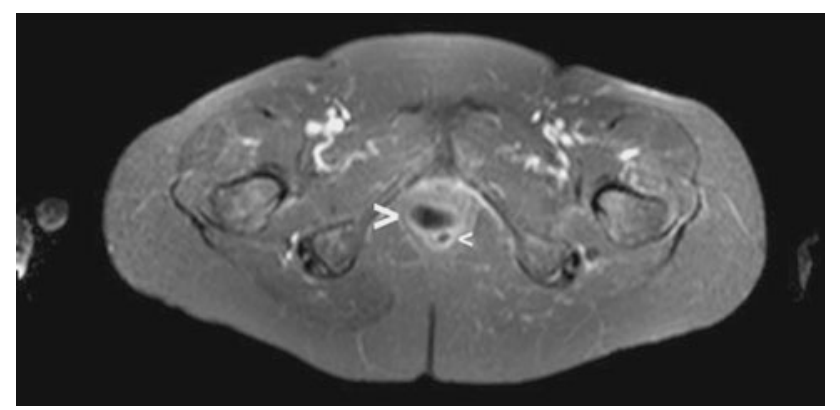

Fig. 1 Coronal MRI revealed a mass within the rectal wall (big arrow) deforming the rectal lumen (small arrow)

A. Serventi $(\bowtie) \cdot$ P. C. Rassu · E. Giaminardi .

G. C. Vitali - G. Brigli

General Surgery Department, San Giacomo Hospital,

Novi Ligure, AL, Italy

e-mail: aserventi@libero.it
Magnetic resonance imaging (MRI) confirmed the presence of an avascular mass, $4 \mathrm{~cm}$ in diameter, confined to the anterior rectal wall (Figs. 1,2).

Intraoperative findings revealed a calcified fecaloma enclosed in a mucousal rectal diverticulum communicating with the rectal lumen with a little opening at the level of the staple line (Figs. 3, 4).

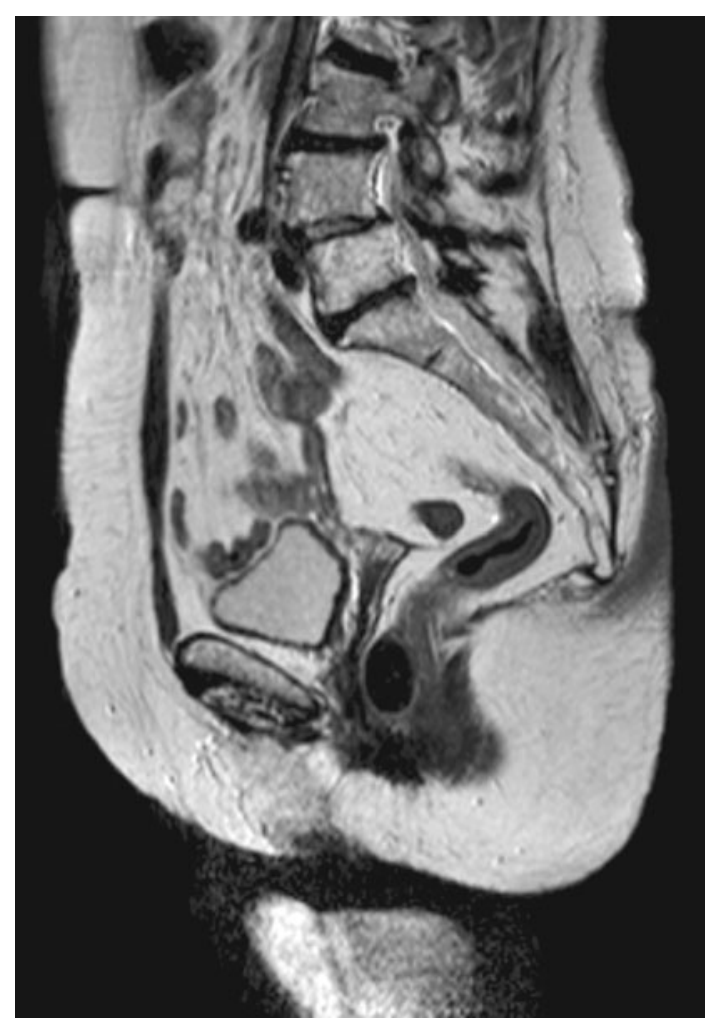

Fig. 2 Sagittal MRI showed the mass was enclosed in rectal mucosa at the level of the rectovaginal septum 


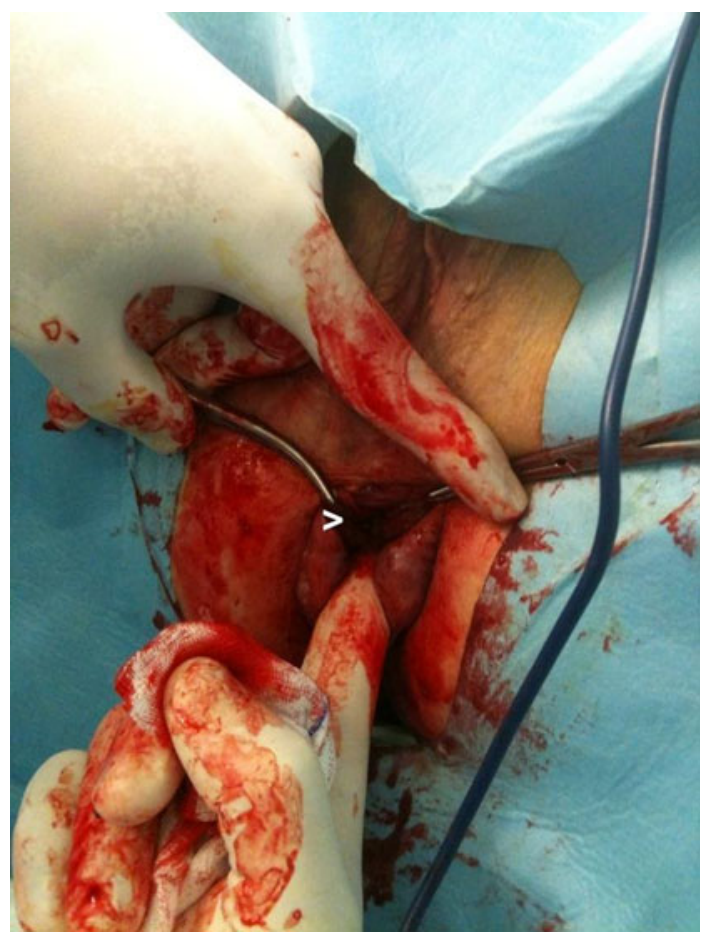

Fig. 3 The opened mucosa (arrow) with a finger in rectal lumen

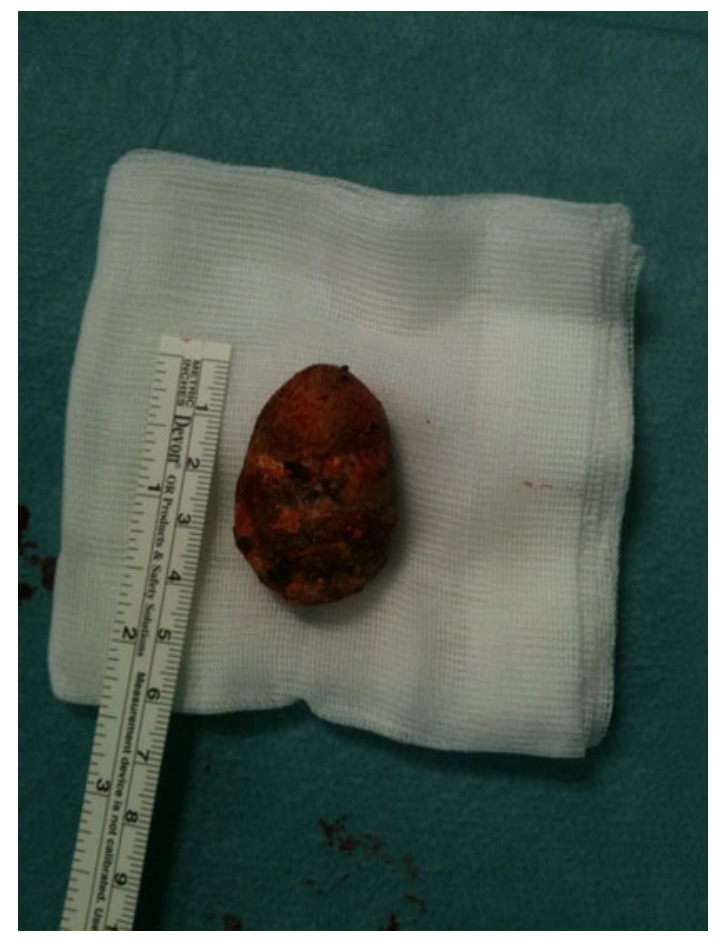

Fig. 4 Fecaloma removed from the mucosal rectal diverticulum 